Supporting information

\title{
Engineered nanotopography on the microfibers of 3D-printed PCL scaffolds to modulate cellular responses and establish an in vitro tumor model
}

Linzhi Jing, ${ }^{\text {acc }}$ Xiang Wang, ${ }^{\text {a Bin Leng, }},{ }^{\mathrm{c}}$ Ningping Zhan, ${ }^{\mathrm{c}}$ Hang Liu, ${ }^{\mathrm{a}, \mathrm{c}}$ Shifei Wang, ${ }^{\mathrm{c}}$ Yuyun ${\mathrm{Lu},{ }^{\mathrm{c}} \mathrm{Jie} \mathrm{Sun}^{*}, \mathrm{~b} \text { and Dejian Huang }}^{*, \mathrm{a}, \mathrm{c}}$

a) National University of Singapore (Suzhou) Research Institute, 377 Linquan Street, Suzhou, Jiangsu 215123, China

b) Department of Mechatronics and Robotics, Xi'an Jiaotong-Liverpool University, 111 Ren'ai Road, Suzhou, Jiangsu 215123, China

c) Department of Food Science and Technology National University of Singapore, 3 Science Drive 2, Singapore 117542

* To whom correspondence should be made. Jie Sun, email: Jie.Sun@xjtlu.edu.cn .

Dejian Huang, email: fsthdi@nus.edu.sg. 


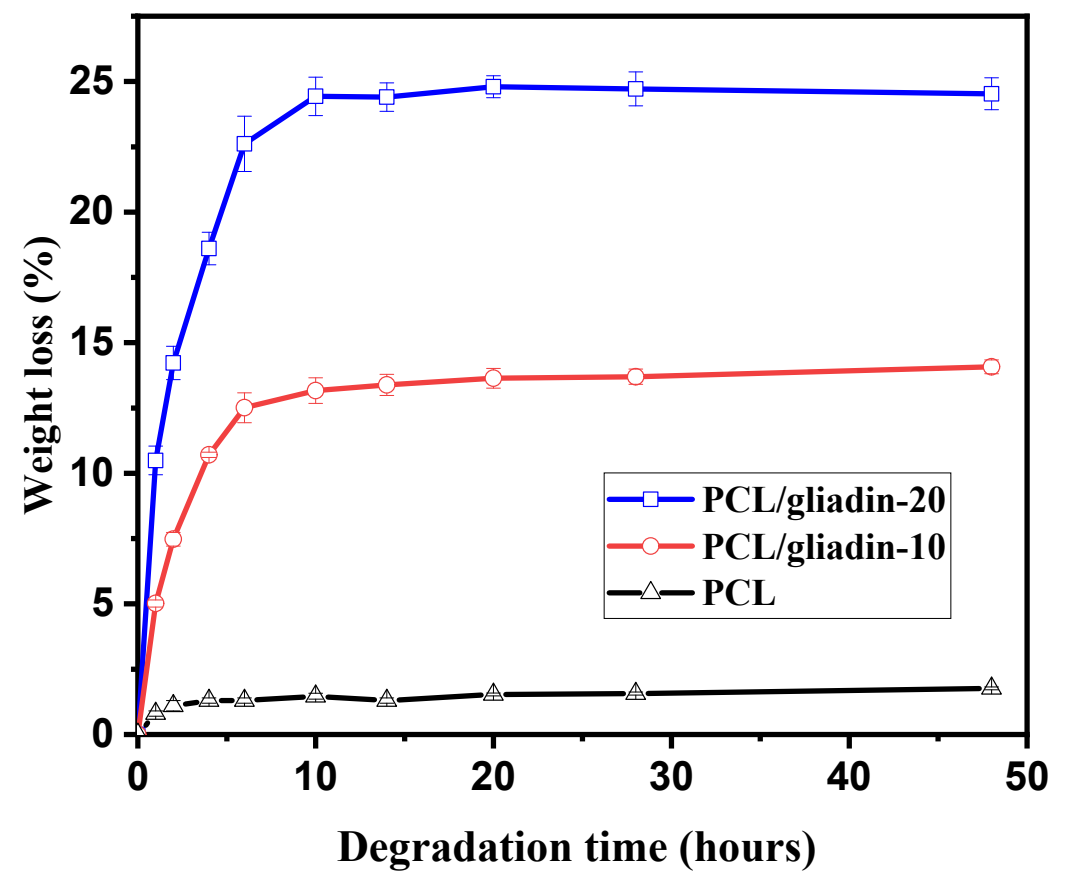

Fig S1. Weight loss profile of PCL and PCL/gliadin scaffolds in 70\% ethanol solution. 
2D plate
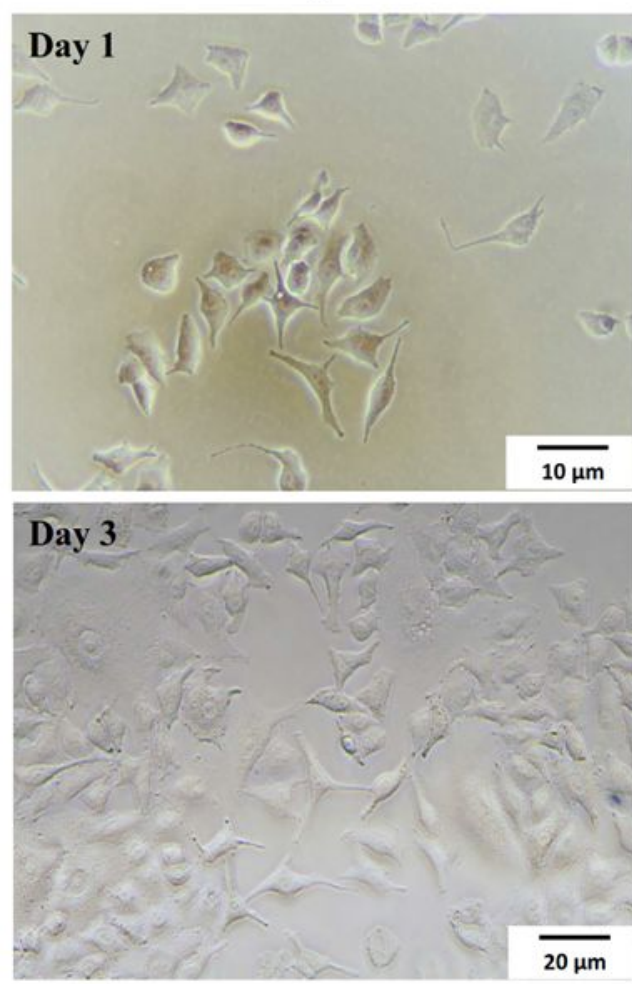

PCL-10-D scaffold
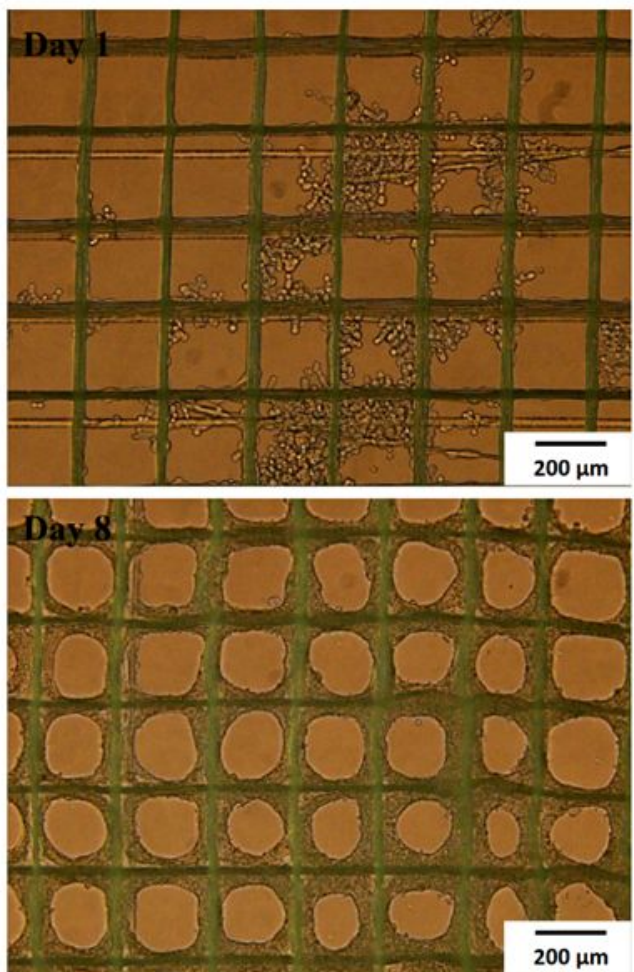

Fig S2. Optical microscope images of cell morphology and superstructure of A549 cells grown on 2D plate and PCL-10-D scaffolds at different culture time.

Table S1. Elemental analysis results of scaffolds before and after leaching treatment. 


\begin{tabular}{lcccccc}
\hline & \multicolumn{3}{c}{ Before treatment } & \multicolumn{3}{c}{ After leaching treatment } \\
\cline { 2 - 7 } & $\mathrm{C}(\%)$ & $\mathrm{H}(\%)$ & $\mathbf{N}(\mathbf{\%})$ & $\mathrm{C}(\%)$ & $\mathrm{H}(\%)$ & $\mathbf{N}(\mathbf{\%})$ \\
\hline PCL & $64.05 \pm 0.04$ & $7.91 \pm 0.02$ & $\mathrm{ND}^{\mathrm{a}}$ & - & - & - \\
PCL/gliadin-10 & $59.81 \pm 0.39$ & $7.95 \pm 0.04$ & $\mathbf{2 . 5 8} \pm \mathbf{0 . 0 8}$ & - & - & - \\
PCL/gliadin-20 & $57.73 \pm 0.28$ & $7.84 \pm 0.07$ & $\mathbf{4 . 7 4} \pm \mathbf{0 . 1 2}$ & - & - & $\mathbf{0}$ \\
PCL-10-D & - & - & - & $59.10 \pm 0.05$ & $7.84 \pm 0.03$ & $\mathbf{1 . 3 8} \pm \mathbf{0 . 0 6}$ \\
PCL-20-D & - & - & - & $60.01 \pm 0.12$ & $7.94 \pm 0.05$ & $\mathbf{0 . 8 2} \pm \mathbf{0 . 0 9}$ \\
\hline
\end{tabular}

${ }^{a} \mathrm{ND}$ refers to non-detectable.

Table S2. Morphological data of printed PCL, PCL/gliadin and PCL-D scaffolds.

\begin{tabular}{lccccc}
\hline Parameters & PCL & PCL/gliadin- & PCL/gliadin- & & \\
& & 10 & 20 & PCL-10-D & PCL-20-D \\
\hline Pore size $(\mu \mathrm{m})$ & $177.3 \pm 10.8$ & $179.3 \pm 7.9$ & $178.5 \pm 7.0$ & $176.2 \pm 10.0$ & $177.5 \pm 12.5$ \\
Top fiber width $(\mu \mathrm{m})$ & $10.0 \pm 1.2$ & $9.4 \pm 0.7$ & $9.1 \pm 1.1$ & $8.4 \pm 0.9$ & $8.3 \pm 0.5$ \\
Bottom fiber width $(\mu \mathrm{m})$ & $19.2 \pm 2.2$ & $18.1 \pm 1.5$ & $17.5 \pm 1.7$ & $16.9 \pm 1.2$ & $16.7 \pm 1.4$ \\
Overall thickness $(\mu \mathrm{m})$ & $79.3 \pm 9.4$ & $72.8 \pm 4.1$ & $78.8 \pm 2.9$ & $71.6 \pm 5.3$ & $74.1 \pm 4.6$ \\
Bulk density $\left(\mathrm{kg} / \mathrm{m}^{3}\right)^{\mathrm{a}}$ & 1100 & 1130 & 1162 & 1100 & 1100 \\
Porosity $(\%)$ & & & & & \\
\end{tabular}

aBulk density was calculated from the densities of PCL and gliadin in composite scaffold. 